Article

\title{
Mindfulness Model Using Polariton Oscillation in Plasmonic Circuit for Human Performance Management
}

\author{
Senee Suwandee ${ }^{1}$, Arumona Edward Arumona ${ }^{2,3,4}$, Kanad Ray ${ }^{5}$, Phichai Youplao ${ }^{3,4, *}$ and \\ Preecha Yupapin $3,4, *$ (D) \\ 1 Kasem Bundit University, Bangkok 10250, Thailand; senee.suw@kbu.ac.th \\ 2 Division of Computational Physics, Institute for Computational Science, Ton Duc Thang University, \\ Ho Chi Minh City 700000, Vietnam; arumonaarumonaedward.st@student.tdtu.edu.vn \\ 3 Computational Optics Research Group, Advanced Institute of Materials Science, Ton Duc Thang University, \\ District 7, Ho Chi Minh City 700000, Vietnam \\ 4 Faculty of Applied Sciences, Ton Duc Thang University, District 7, Ho Chi Minh City 700000, Vietnam \\ 5 School of Applied Sciences, Amity University Rajasthan, Jaipur 302006, India; kanadray00@gmail.com \\ * Correspondence: phichai.yo@tdtu.edu.vn (P.Y.); preecha.yupapin@tdtu.edu.vn (P.Y.)
}

Received: 2 April 2020; Accepted: 12 June 2020; Published: 8 July 2020

\begin{abstract}
We have proposed that human life is formed on a space and time function relationship basis, which is distorted after fertilization in the ovum, from which growth is generated by a space-time distortion against the universe's gravity. A space-time distortion's reduction can be managed by space and time separation, which is known as mindfulness. A space-time distortion in human cells is configured by a polariton traveling in a gold grating film, which can be employed to investigate mindfulness characteristics. Mindfulness is the steady state of the time function of energy after the separation. Energy levels of mindfulness based on polariton aspects are categorized by a quantum number (n), which can be reduced to be a two-level system called Rabi oscillation by a successive filtering method. We have assumed a cell space-time distortion can reduce to reach the original state, which is the stopping state. Mindfulness with a certain frequency energy level of $n=2$ was achieved. Several techniques in the practice of mindfulness based on successive filtering called meditation are given and explained, where the required levels of the mindfulness state can be achieved. The criteria of the proposed method are a low energy level (n) and high frequency (f) outputs, which can apply to having a working performance improvement.
\end{abstract}

Keywords: mindfulness; working performance; polariton; successive filtering; Rabi oscillation; plasmonic circuit

\section{Introduction}

Mindfulness is the saturation energy of the mind and has been studied and used for humans in various applications [1], where the use of mindfulness for psychology [2-5] and health [6-10] is reported. The study of mindfulness and working performance has recently been reported [11-14], however, mindfulness energy levels and characteristics have never been investigated. By using the wave-particle aspect of the human mind energy wave, the mindfulness level can be configured and used for various forms of investigations. Wave-particle is a paradox pair localized at the same location in a universe [15], which can be dark (nothing) or bright (something) energy forms. Since the vibration is induced by bright and dark energy distortion, a Plank's length [16] is formed and continuously oscillated inside the event horizon. The first wave and particle projection can be observed [17] at the event horizon edge, where the related distortion quantity between the entangled pair is established, 
recognized as time. The speed of light can be calculated from the space-time distortion, which is of a constant value. The wave-particle vibration energy is now quantized after the event horizon, from which the space-time distortion has begun, and the universe is formed [16]. Human life has also been formed by the wave-particle aspect, consisting of both material and nonmaterial, which is also originally from vibrations in the initial state. Initially, a sperm generated a shock wave known as a soliton pulse, coupled with ionic dipoles in an egg, where life began $[18,19]$. The heart and blood content formed by the sperm and egg is distributed to the whole zygote. The coupling between the sperm shock wave and the ionic dipole oscillation frequency becomes the heartbeat cycle. The space distortion involved after the event horizon border gives more space-time distortion, i.e., more body gravity. Continuous human growth generates an increase in the space-time transmission networks, connected to the brain as the central processing unit. [20,21]. Human organs are formed by the space-time distortion and quantized energy and linked by the transmission networks $[15,19,22,23]$. Human growth regarding space-time distortion can be adjusted automatically. A differential blood pressure occurs when the growth becomes unbalanced with gravity, which can be described by $\rho g h$, where $\rho$ is the blood density, $g$ is the gravity, and $h$ is the blood content height. By using successive filtering, the polariton space-time distortion can be observed by Plank's radiation [18,24], in which the space-time distortion can be traced back and reach the Plank's radiation locations. The Rabi frequency can be formed by the two-level system $[17,25]$. Similarly, working performance and quality can be achieved by a focus of one thing while working in the same way as successive filtering, where the uncertainty can be minimum [17]. The concentration can give the resonance between the body and mind while working, where the optimum mindfulness level can generate a small mind space-time distortion, leading to the real mind state in nature. The human body formed and grew as a symmetrical structure $[19,21,22,25]$. Therefore, cell communication within the body can be controlled to have stereo signal distribution, which is suitable for space-time distortion control. In this case, the space-time successive filtering technique called meditation is suggested for space-time distortion reduction. We assumed that the human mind is formed by the polariton transmission network [26,27], where the brain is the central processing unit. Successive filtering of the human transmission signals can be applied to have mindfulness with a focused concentration. Meditation is applied to have high-level mindfulness, where the internal and external space-time distortions can be ignored. Therefore, the human mind's streamline network can be adjusted to having the minimum space-time distortion. When there is no external and internal noise effect to the mind and body, the space-time distortion almost vanishes. Moreover, a high concentration of high-level mindfulness can achieve the body and mind's working resonance, which can lead to having high performance. The simulation results are obtained by the Matlab program. The results are interpreted and discussed relative to the proposed theoretical background.

\section{Mindfulness Model}

The first human space-time observation formed by two different spaces is the two-level system, which has space and time functions. Firstly, one is from a sperm and an egg, which becomes a zygote after fertilizing. The distortion in space (zygote) is continuous in Plank's length (energy) until the event horizon [16,22], the projection from the first to the second resonant space-induced time function involved. A zygote formed by a wave-particle projection oscillates by the Rabi oscillation frequency. This is the two-level system [17,25], where the energy is quantized. The zygote is developed to be a baby, from which the mind energy level can be changed because of the growth from the space-time distortion.

The coupling between a sperm shock wave and an egg ionic dipole generates the plasmonic wave oscillation with a frequency $f$. The resonant space-time function outside the event horizon is given by $[15,17]$

$$
H(z, t)=S(z) \cdot D(z, t)=A(z) e^{ \pm i 2 \pi f t}
$$


where $S(z)$ is the first space function formed by a sperm and an egg, $D(z, t)$ is the second space-time function formed by the resonant environment, and $+\Delta t$ and $-\Delta t$ are the growth and decay time distortions based on the energy conservation, respectively.

Mindfulness is formed when the mind function is separated from the space function, in which $H(t)$ is the time-dependent function, which is written as

$$
H(t)=\text { C. } e^{ \pm i 2 \pi f t}
$$

where the signs $( \pm)$ represent the spin-up and -down of the polariton spins.

Each state of mindfulness (n) is a steady-state of Equation (1), which is satisfied with Equation (3). The space function is a constant, which is expressed by

$$
\frac{d H(t)}{d t}=0
$$

The mind function is maximum at the steady state, which is called delightfulness. It is the mindfulness transition state, where $\mathrm{n}$ is the state number, and $\mathrm{n}=1,2,3, \ldots$. The human mental energy level (n) can reach a certain high-level, and the third eye behavior can be formed, from which the communication known as telepathy can be performed. The power increases due to the shorter switching time in the mind's successive filtering process. However, mental energy is always conserved.

The plasmonic circuit has the form of the panda ring as shown in Figure 1. The circuit consists of two linear bus waveguides and a silicon microring as the center ring with two small rings at its sides. The gold gratings at the center ring are described by the Drude model [26-29] which explains the behavior of electrons in the gold gratings when illuminated by light as given in Equations (4) and (5).

$$
\epsilon(\omega)=1-\frac{n e^{2}}{\epsilon_{0} m \omega^{2}}
$$

where $\epsilon_{0}$ is defined as relative permittivity, $m$ is defined as mass, $e$ is defined as electron charge, and $n$ is defined as electron density. At resonance, $\omega_{p}$ is defined as plasma frequency resonance given as

$$
\omega_{p}=\left[\frac{n e^{2}}{\epsilon_{0} m}\right]^{-\frac{1}{2}}
$$

$n=\frac{\omega_{p}^{2} \epsilon_{0} m}{e^{2}}$ is defined as the electron density which results in plasmonic wave oscillation when in an electric field. The Bragg wavelength is defined as $\lambda_{B}=2 n_{e} \Lambda$, where $\bigwedge$ is defined as the grating period, and $n_{e}$ is defined as the effective refractive index. The Kerr effect is the nonlinear effect present in the circuit given as $n=n_{0}+n_{2} \mathrm{I}=n_{0}+n_{2} P / A_{\text {eff }}$, where $n_{0}$ is defined as the linear refractive index, $n_{2}$ is defined as the nonlinear refractive index, I is defined as the optical intensity, $P$ is defined as the optical power, and $A_{e f f}$ is defined as the effective mode core area. The two small rings at the side of the center ring induce the nonlinearity effect as the small rings act as phase modulators. At the two outputs of the plasmonic circuit, the normalized intensities are given as

$$
\begin{gathered}
\frac{I_{\text {th }}}{I_{\text {in }}}=\left[\frac{E_{\text {th }}}{E_{\text {in }}}\right]^{2} \\
\frac{I_{\text {drop }}}{I_{\text {in }}}=\left[\frac{E_{\text {drop }}}{E_{\text {in }}}\right]^{2}
\end{gathered}
$$



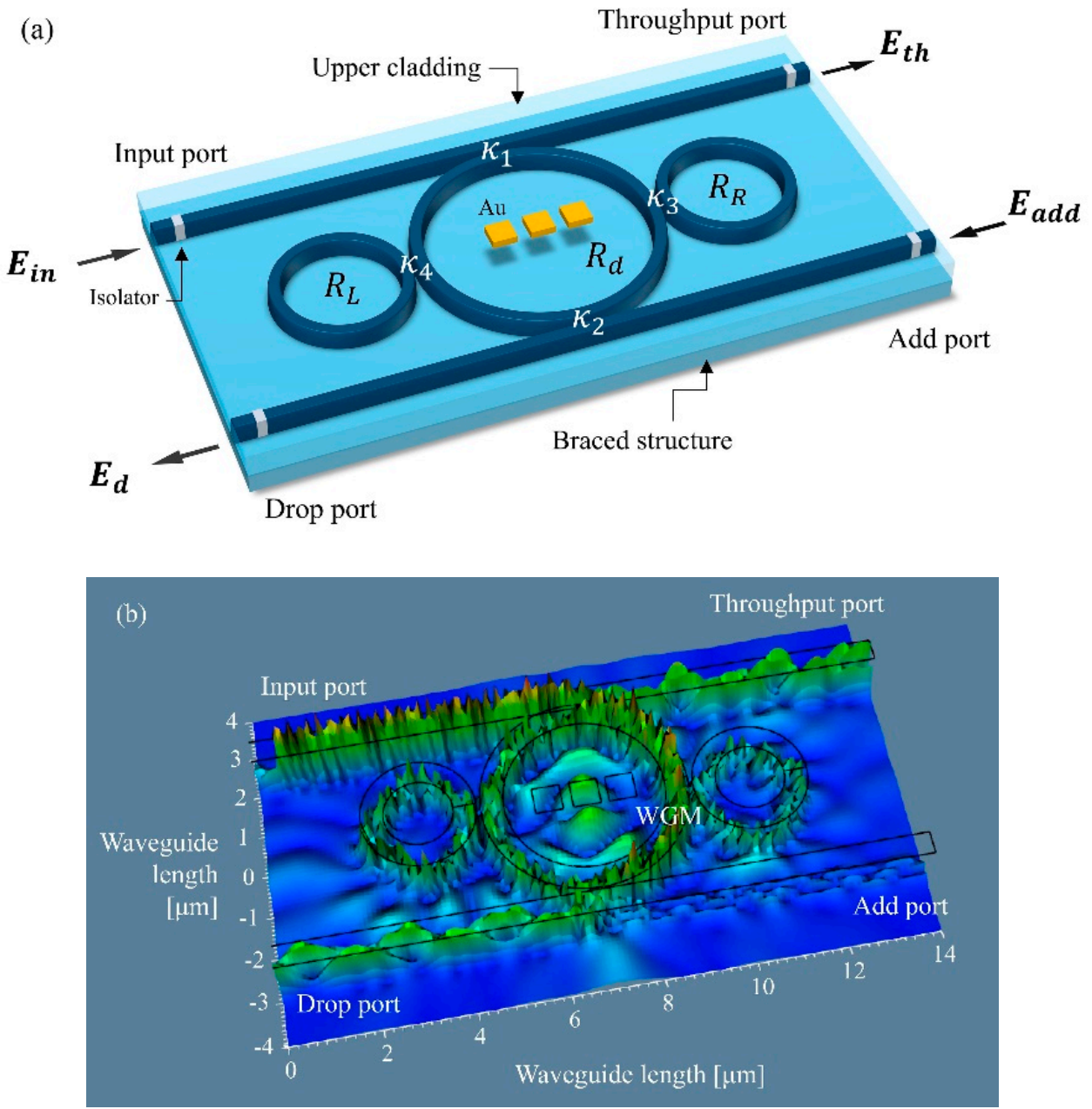

Figure 1. The schematic of a successive filtering circuit applied for the mindfulness model and simulation, which is a plasmonic circuit, where (a) is the schematic circuit, and (b) the trapped electron distribution in the circuit. The gold gratings are embedded within the centering to form the electron cloud distribution in the silicon circuit. The input, throughput, add port, and drop ports are Ein, Eth, Eadd, and Ed, respectively. Rd: central ring radius, RR and RL: side ring radii, and K1-K4: coupling constants. The isolator is applied to protect the feedback against the input source.

\section{Simulation Results and Discussions}

Various techniques of human mind development based on mindfulness and meditation have been reported [14,19,27,29-37]. Most of them have a common technique known as meditation, where in practice, eventually, mental concentration (focus) is achieved after mindfulness. Mindfulness that can be modeled by the energy-time function based on polariton successive filtering was reported $[18,19]$, which can be applied to human working performance development. The energy-time function has separated from the space function, becoming a time-dependent function, and the Matlab program is applied to form the polariton successive filtering results. The successive round trip of the resonant results is 20,000. The simulation parameters are given in Table 1. As explained by $[15,17]$ using Equations (1) and (2), the plot of the mindfulness in terms of the electron densities (ED) is shown in Figure 2. Figure 3 shows the delightfulness in the wavelength and frequency domains, where the blue and red colors are the polaritons' spin-up and spin-down. The consciousness plot is shown in Figure 4 and the time slot on the two sides of time. The mindfulness level can be categorized and described based on the space-time distortion. Firstly, the space (body) function requires to have balance and be clean. Secondly, the time-energy function is separated from the space function, i.e., time dependence. 
Successive filtering is applied to having mindfulness, where the resonance between the body (space) and mind (time) distortion is the requirement. In calculation, when the distortion in space-time becomes a small value, the concentration of energy is squeezed at the forehead (third eye), which can be tuned from the frequency range from THz-Peta Hz. By concentrating on one thing for some time, the mind signals can reach a steady state, which is not affected by the external or internal environment. In Figure 4, the first observation of the space-time distortion is the smallest distortion, which is configured as quantum consciousness [23,32]. They proposed that an entangled pair is processed by the polariton spin-up and -down and can be used to form the quantum consciousness. In principle, the human communication networks can transmit via a mind (time-energy) network, where the polariton spins can transfer the changes with the cell electron clouds [23], wherein the quantum cellular automata are processed to form the quantum consciousness. In Figure 5 , the stopping condition $\Delta t \rightarrow 0$ is the mindfulness at the steady state, without violence, where the change in frequency and wavelength does not affect the free state (emptiness). The vertical line of the time, frequency, and wavelength results on the electron densities (ED) with power variation can link to the suitable energy level and quantum number. The energy quantum number is a small number to be the two-level system, where $\mathrm{n}=2$, and a Rabi oscillation occurs. If $\mathrm{n}=1$, the Rabi oscillation vanishes, i.e., quantum physics is collapsed. This means that the system has no violation (independence) from the exciting environment. The large quantum number causes a lower frequency oscillation, for instance, if $n=100$, the frequency (f) is 10 times lower than $n=10$. The Rabi oscillation is the two-level system having a very high frequency, which is the oscillation without an excited environmental effect.

Table 1. The selected simulation parameters.

\begin{tabular}{|c|c|c|c|}
\hline Parameters & Symbols & Values & Units \\
\hline Input power & $\mathrm{P}$ & 150 & $\mathrm{~mW}$ \\
\hline Length of silicon linear waveguide & $\mathrm{L}$ & 14.0 & $\mu \mathrm{m}$ \\
\hline Si center ring radius & $\mathrm{R}_{\mathrm{d}}$ & 2.0 & $\mu \mathrm{m}$ \\
\hline Left small ring radius & $\mathrm{R}_{\mathrm{L}}$ & 1.0 & $\mu \mathrm{m}$ \\
\hline Right small ring radius & $\mathrm{R}_{\mathrm{R}}$ & 1.0 & $\mu \mathrm{m}$ \\
\hline Au dielectric constant [38] & $\epsilon_{0}$ & 6.9 & \\
\hline Au permittivity [38] & $\epsilon$ & 10.0 & \\
\hline Au grating width & $\mathrm{W}_{\mathrm{AU}}$ & 0.4 & $\mu \mathrm{m}$ \\
\hline Au thickness & d & 0.2 & $\mu \mathrm{m}$ \\
\hline Au length & $\mathrm{L}_{\mathrm{AU}}$ & 1.6 & $\mu \mathrm{m}$ \\
\hline Refractive index of $\mathrm{Au}[38]$ & $\mathrm{n}$ & 1.80 & \\
\hline Insertion loss & $\gamma$ & 0.5 & $\mathrm{~dB}$ \\
\hline Coupling coefficient & $\mathrm{k}$ & $0.06-0.70$ & \\
\hline Refractive index Si [38] & $n_{S i}$ & 3.42 & \\
\hline Si nonlinear refractive index [39] & $n_{2}$ & $1.3 \times 10^{-13}$ & $\mathrm{~m}^{2} \mathrm{~W}^{-1}$ \\
\hline Optical center wavelength & $\lambda_{1}$ & 1.50 & $\mu \mathrm{m}$ \\
\hline Waveguide core effective [39] & $A_{e f f}$ & 0.50 & $\mu \mathrm{m}^{2}$ \\
\hline Waveguide loss & $\alpha$ & 0.50 & $\mathrm{~dB} .(\mathrm{cm})^{-1}$ \\
\hline Plasma frequency [40] & $\omega_{\mathrm{p}}$ & $1.2990 \times 10^{16}$ & $\operatorname{radsec}^{-1}$ \\
\hline Electron mass & $\mathrm{m}$ & $9.11 \times 10^{-31}$ & $\mathrm{~kg}$ \\
\hline Electron charge & $\mathrm{e}$ & $1.6 \times 10^{-19}$ & Coulomb \\
\hline Permittivity of free space & $\epsilon_{o}$ & $8.85 \times 10^{-12}$ & $\mathrm{Fm}^{-1}$ \\
\hline Reduced Planck's constant & $\hbar$ & 1.00 & ARU \\
\hline
\end{tabular}




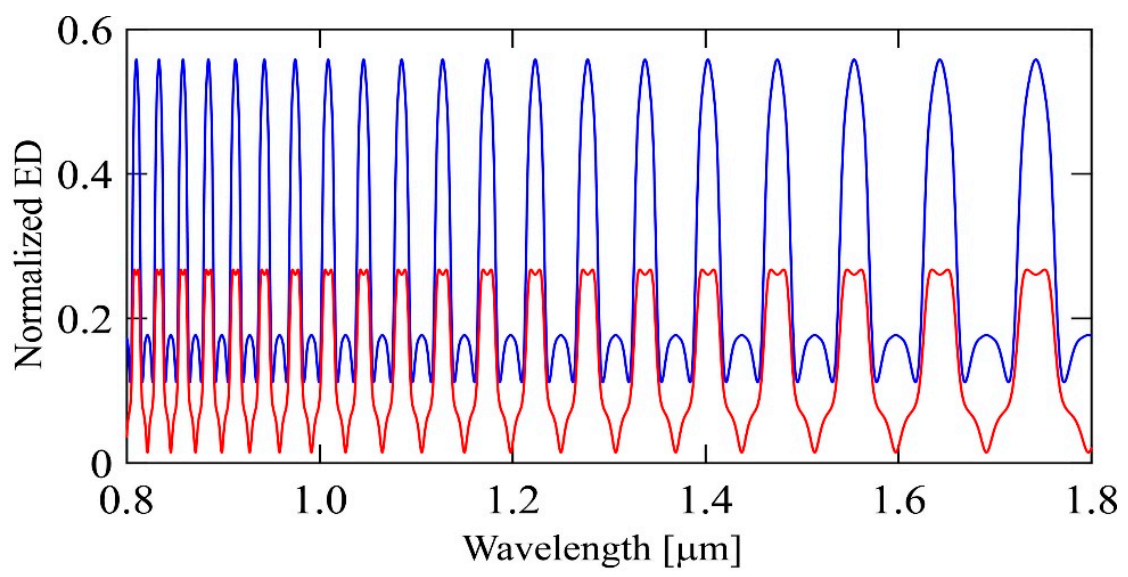

Figure 2. The mindfulness simulation signals where the blue and red colors are the polaritons' spin-up and spin-down. This is the steady-state signals at the optimum condition. A Rabi oscillation occurs when the energy level is reduced to be $n=2$. The oscillation is collapsed, when $n=1$, and the energy state becomes a continuous energy state (only one level).
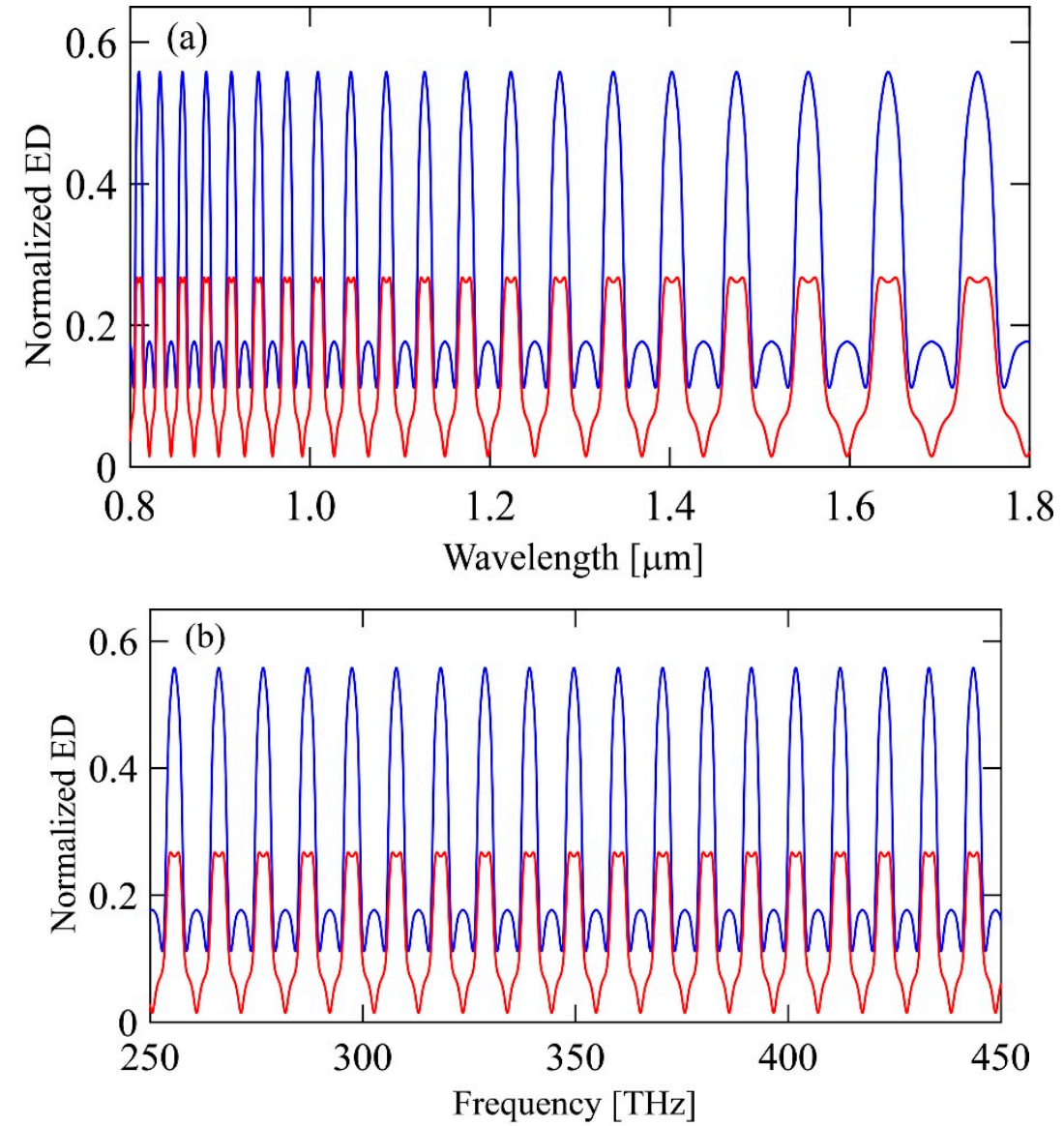

Figure 3. The plot of the delightfulness simulation signals where (a) is the wavelength domain, and (b) is the frequency domain where the blue and red colors are the polaritons' spin-up and spin-down. This is the steady state of the energy-time function in terms of wavelength and frequency, respectively. 


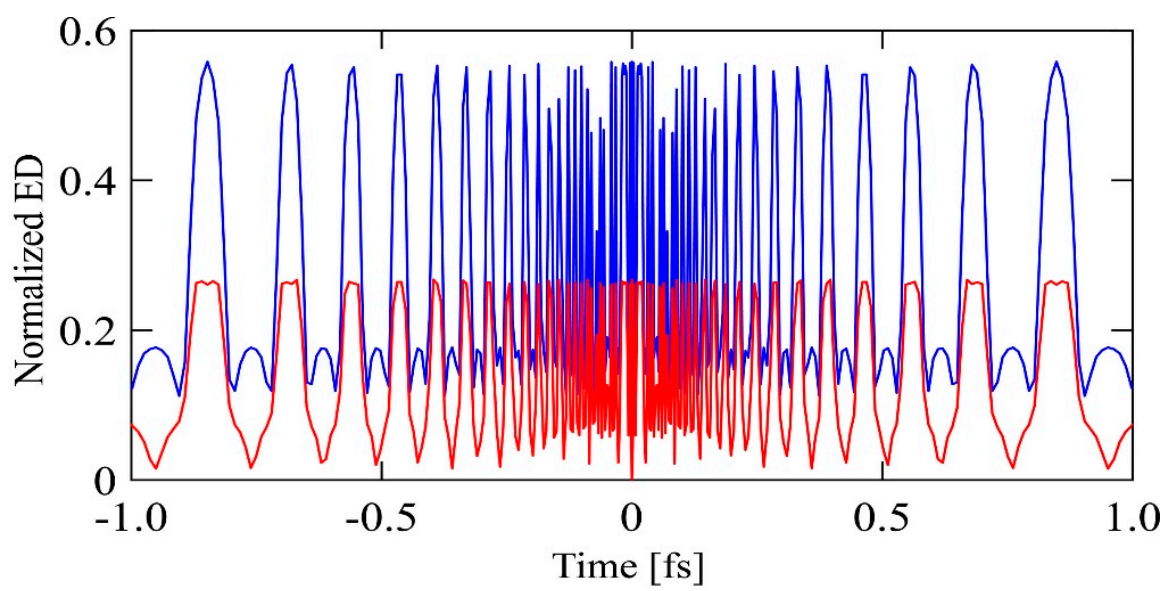

Figure 4. The plot of consciousness signals where the blue and red colors are the polaritons' spin-up and spin-down. The full time slot of the consciousness can be detected and recorded. The gap between the spin-up and -down is the steady-state, which is the stopping state, which is no violation of the exciting environment. The two-level system is strongly confirmed when $\Delta t \rightarrow 0$, where a high frequency $(\Delta f \rightarrow 0)$ is exhibited. The finest energy (high frequency) is achieved, which is the non-violent energy state, i.e., one continuous energy level.

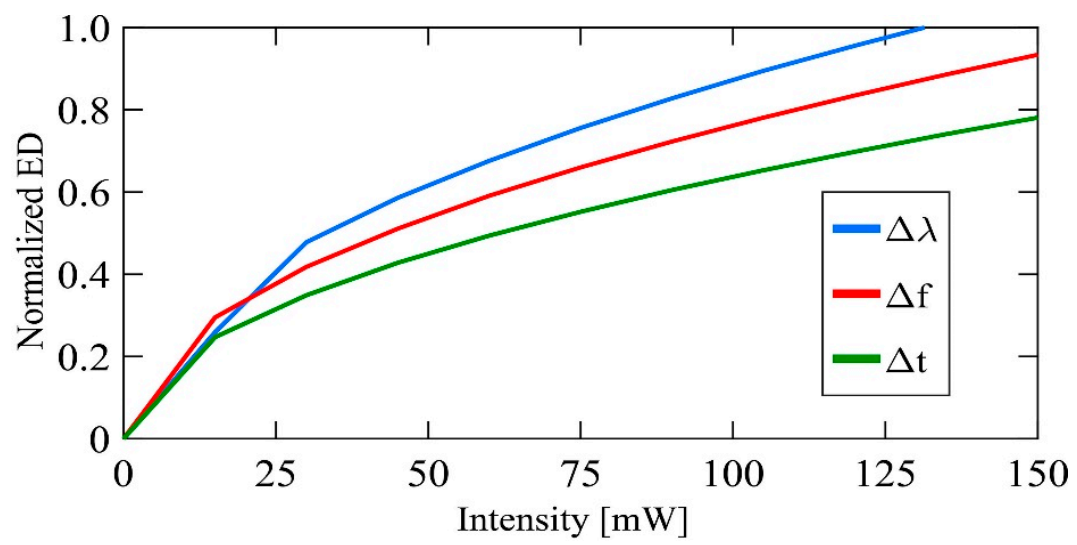

Figure 5. The plot of the mindfulness violation between the normalized electron densities (ED) and input power, where the changes in delta wavelength $(\Delta \lambda)$, time $(\Delta t)$, and frequency $(\Delta f)$ are set as the initial state when $\Delta t \rightarrow 0$. This is the stopping state.

By using the circuit operation principle, the circuit characteristics can be applied to accommodate the quantum consciousness, working performance, and humanoid ethics in practice based on meditation. Firstly, the human quantum consciousness can be formed by a space-time plasmonic circuit, as shown in Figure 1, which was reported [23]. A polariton successive filtering circuit is applied in the manipulation. The minimum noise effect of mind signals obtained during sleeping (dream) can reach the high-level mind state. In application, a circuit can connect to the human brain signals, from which the space-time distortion can be reduced and vanished. The dream is the space-time distortion remained constant while sleeping, in which the quantum consciousness randomly occurres in the mind network. The wake-up makes the consciousness signals covered by noisy signals, and the dream forgotten. The humanoid brain using mindfulness [21-23] can be constructed and operated to achieve quantum consciousness, where mindfulness is achieved by a successive filtering circuit. Secondly, mindfulness development and working performance can be achieved through high-frequency mindfulness, where the human's lowest frequency Rabi oscillation can be generated. The higher mind frequency can be obtained by meditation based on successive filtering techniques. The best performance criteria for the human mind energy level can be obtained by the successive filtering method. Quantum consciousness occurs when 
the space-time distortion is vanishing. The highest mindfulness level and the finest energy with the lowest mind power can be achieved, while the best performance remains. Finally, humanoid ethics can be controlled and applied for safety management. Mindfulness can lead the mind signals to stop (stand still) for a decision, which has the advantage of the final decision. The space-time distortion affected the gravity and growth of the mind and body. The external space-time distortion was introduced by the six sensors, which are the nose, eyes, tongue, ears, skin (body), and mind sensors. The human body internal space-time distortion is induced by the chemical and mechanical process of the body and links to the mind. The parameters are $\Delta \mathrm{x}, \Delta \mathrm{t}, \Delta \mathrm{T}$, and $\Delta \mathrm{v}$, which result in the polariton space-time distortion [15,17], where $\mathrm{x}$ is the space, $\mathrm{t}$ is the time, $\mathrm{T}$ is the temperature, and $\mathrm{v}$ is the speed of light in vacuum. Space-time distortion changes from the new location are also required in successive filtering for a certain period for each person. The final decision with no ignorance and high-level mindfulness will obtain the optimum performance. There is no space-time distortion.

From Equation (1), the mindfulness is the orthonormal of $\boldsymbol{H}(\boldsymbol{z}, \boldsymbol{t})$, which is expressed by $<\boldsymbol{H}(\boldsymbol{z}, \boldsymbol{t}) \boldsymbol{l} \boldsymbol{H}(\boldsymbol{z}, \boldsymbol{t})^{*}>=1$, which means the modulated signals with the energy-time function are optimum without any space-time distortion [17]. A period of mindfulness is called meditation (focus). Mindfulness and meditation are positive distortions that can offer aura generation. In principle, the space-time distortion control of the polariton transmission can be configured into the positive or negative side of the signal oscillation. In complex cells like human cells, the polariton oscillation can introduce both a positive and negative energy-time distortion, as shown in Equation (2). The positive distortion can induce a cell blue shift, while the negative one cannot (Ali et al., 2018). A cell blue shift can be applied for cell healing and disinfectant application. In meditation, the stopping situation is achieved when $\Delta t \rightarrow 0$, which means that the disease will disappear when the distortion has vanished (Ali et al., 2019). By using successive filtering, the mindfulness signals can be filtered and eventually have the two-level system [17], which can process the quantum consciousness. The polariton spin-up and -down are applied to form quantum bits $(0,1)$, which are useful for a type of quantum processing called quantum cellular automata.

\section{Conclusions}

We have proposed the technique of human working performance development by using the mindfulness successive filtering method based on polariton manipulation within a two-level system. A high-frequency and small quantum number of the polariton states are required to have mindfulness development. Successive filtering will lead to having high power due to the shorter switching time (high frequency), while low energy levels will lead to having a Rabi oscillation. Finally, the stopping state is established. By using meditation in everyday life, the best working performance can be achieved when the synchronous between the mind and body is an active operation, where the low mindfulness power will be the target. Simulation results show that the Rabi oscillation behaviors based on polariton successive filtering can be configured as the mindfulness interpretation. In applications, mindfulness development can be applied for human performance in everyday life, where a small space-time distortion is the target. The use of a mindfulness model can also be applied for the quantum consciousness and humanoid brain, which can lead to having an ethical humanoid robot and a peaceful society.

Author Contributions: S.S. proposed the concept of the work and discussion; A.E.A.: Simulation and discussion; K.R.: Writing, discussion, and correction, P.Y. (Phichai Youplao): Graphical work and discussion; P.Y. (Preecha Yupapin): Writing, revision, and discussion. All authors have read and agreed to the published version of the manuscript.

Funding: This research received no external funding.

Acknowledgments: The authors would like to acknowledge to Ton Duc Thang University, Vietnam for the research facility.

Conflicts of Interest: The authors have declared that this work has no conflict of interest. 


\section{References}

1. Bishop, S.; Lau, M.; Shapiro, S.; Carlson, L.; Anderson, N.; Carmody, J.; Segal, Z.; Abbey, S.; Speca, M.; Velting, D.; et al. Mindfulness: A proposed operational definition. Clin. Psychol. Sci. Pract. 2004, 11, $230-241$. [CrossRef]

2. Barnes, S.; Brown, K.; Krusemark, E.; Campbell, W.; Rogge, R. The role of mindfulness in romantic relationship satisfaction and responses to relationship stress. J. Marital. Fam. Ther. 2007, 33, 482-500. [CrossRef] [PubMed]

3. Brown, K.; Ryan, R. The benefits of being present: Mindfulness and its role in psychological well-being. J. Personal. Soc. Psychol. 2003, 84, 822-848. [CrossRef] [PubMed]

4. Farb, N.; Anderson, A.; Mayberg, H.; Bean, J.; McKeon, D.; Segal, Z. Minding one's emotions: Mindfulness training alters the neural expression of sadness. Emotion 2010, 10, 25-33. [CrossRef] [PubMed]

5. Wachs, K.; Cordova, J. Mindful relating: Exploring mindfulness and emotion repertoires in intimate relationships. J. Marital. Fam. Ther. 2007, 33, 464-481. [CrossRef] [PubMed]

6. Bazarko, D.; Cate, R.; Azocar, F.; Kreitzer, M. The impact of an innovative mindfulness-based stress reduction program on the health and well-being of nurses employed in a corporate setting. J. Workplace Behav. Health 2013, 28, 107-133. [CrossRef]

7. Hofmann, S.; Sawyer, A.; Witt, A.; Oh, D. The effect of mindfulness-based therapy on anxiety and depression: A meta-analytic review. J. Consult. Clin. Psychol. 2010, 78, 169-183. [CrossRef]

8. Gross, C.; Kreitzer, M.; Reilly-Spong, M.; Wall, M.; Winbush, N.; Patterson, R.; Mahowald, M.; Cramer-Bornemann, M. Mindfulness-based stress reduction vs. pharmacotherapy for primary chronic insomnia: A pilot randomized controlled clinical trial. Explore 2011, 7, 76-87. [CrossRef]

9. Goldin, P.; Gross, J. Effects of mindfulness-based stress reduction (MBSR) on emotion regulation in social anxiety disorder. Emotion 2010, 10, 83-91. [CrossRef]

10. Shonin, E.; Van Gordon, W.; Griffiths, M. Mindfulness-based interventions: Towards mindful clinical integration. Front. Psychol. 2013, 4, 194. [CrossRef]

11. Aikens, K.; Astin, J.; Pelletier, K.; Levanovich, K.; Baase, C.; Park, Y.; Bodnar, C. Mindfulness goes to work: Impact of an online workplace intervention. J. Occup. Environ. Med. 2014, 56, 721-731. [CrossRef] [PubMed]

12. Huang, S.; Li, R.; Huang, F.; Tang, F. The potential for mindfulness-based intervention in workplace mental health promotion: Results of a randomized controlled trial. PLOS ONE 2015, 10, e0138089. [CrossRef]

13. Hülsheger, U.; Alberts, H.; Feinholdt, A.; Lang, J. Benefits of mindfulness at work: The role of mindfulness in emotion regulation, emotional exhaustion, and job satisfaction. J. Appl. Psychol. 2012, 98, 310-325. [CrossRef]

14. Shiba, K.; Nishimoto, M.; Sugimoto, M.; Ishikawa, Y. The association between meditation practice and job performance: A cross-sectional study. PLoS ONE 2015, 10, e0128287.

15. Ali, J.; Youplao, P.; Amiri, I.S.; Pornsuwancharoen, N.; Yupapin, P. Hibernation model based on polariton successive filtering. Natl. Acad. Sci. Lett. 2019. [CrossRef]

16. Bekenstein, J.D. Black Holes and Entropy. Phys. Rev. D 1973, 7, 2333-2346. [CrossRef]

17. Arumona, A.E.; Amiri, I.S.; Singh, G.; Yupapin, P. Full-time slot teleportation using unified space-time function control. Microw. Opt. Technol. Lett. 2020, 62, 1577-1580. [CrossRef]

18. Ali, J.; Pornsuwancharoen, N.; Youplao, P.; Amiri, I.S.; Yupapin, P. Characteristics of an on-chip polariton successively filtered circuit. Results Phys. 2018, 11, 410-413. [CrossRef]

19. Youplao, P.; Pornsuwancharoen, P.; Amiri, I.S.; Jalil, M.A.; Aziz, M.S.; Ali, J.; Singh, G.; Yupapin, P.; Grattan, K.T.V. Microring stereo sensor model using kerr-vernier effect for bio-cell sensor and communication. Nano Commun. Netw. 2018, 17, 30-35. [CrossRef]

20. Bunruangses, M.; Youplao, P.; Amiri, I.S.; Pornsuwancharoen, N.; Yupapin, P. Brain sensor and communication model using plasmonic microring antenna network. Opt. Quantum Electron. 2019, 51, 349. [CrossRef]

21. Bunruangses, M.; Youplao, P.; Amiri, I.S.; Pornsuwancharoen, N.; Puntawanunt, S.; Singh, G.; Yupapin, P. Microring distributed sensors using space-time function control. IEEE Sens. J. 2020, 20, 799-805. [CrossRef]

22. Bunruangses, M.; Youplao, P.; Amiri, I.S.; Pornsuwancharoen, N.; Yupapin, P. Double vision model using space-time function control within silicon microring system. Silicon 2019. [CrossRef]

23. Bunruangses, M.; Youplao, P.; Amiri, I.S.; Pornsuwancharoen, N.; Punthawanunt, S.; Singh, G.; Yupapin, P. Electron Cloud Density Generated by Microring-Embedded Nano-grating System. Plasmonics 2020, 15, 543-549. [CrossRef] 
24. Pornsuwancharoen, N.; Youplao, P.; Amiri, I.S.; Ali, J.; Yupapin, P. On-chip polariton generation using an embedded nanograting microring circuit. Results Phys. 2018, 10, 913-916. [CrossRef]

25. Noorden, A.F.A.; Chaudhary, K.; Bahadoran, M.; Aziz, M.S.; Jalil, M.A.; Tiong, O.C.; Ali, J.; Yupapin, P. Rabi oscillation generation in the microring resonator system with double-series ring resonators. Optoelectron. Lett. 2015, 11, 342-347. [CrossRef]

26. Poznanski, R.R.; Cacha, L.A.; Al-Wesabi, Y.M.S.; Ali, J.; Bahadoran, M.; Yupapin, P.P.; Yunus, J. Solitonic conduction of electrotonic signals in neuronal branchlets with polarized microstructure. Sci. Rep. 2017, 7, 2746. [CrossRef]

27. Youplao, P.; Pornsuwancharoen, N.; Amiri, I.S.; Punthawanunt, S.; Yupapin, P. Deep meditation model based-on polariton successive filtering method. Yoga Phisio 2019, 43, 207-211.

28. Derkachova, A.; Kolwas, K. Size Dependence of Multipolar Plasmon Resonance Frequencies and Damping Rates in Simple Metal Spherical Nanoparticles. Eur. Phys. J.-Spec. Top. 2007, 144, 93-99. [CrossRef]

29. Tunsiri, S.; Nopparat, T.; Thanunchai, T.; Somsak, M.; Yupapin, P. Microring switching control using plasmonic ring resonator circuits for super-channel use. Plasmonics 2019, 14, 1669-1677. [CrossRef]

30. Prince, G. Controlling level splitting by strong coupling of surface plasmon resonances with rhodamine-6g on a gold grating. Plasmonics 2018, 13, 2067-2077.

31. Kabat-Zinn, J. Wherever You Go, There You Are: Mindfulness Meditation in Everyday Life; Hachette Books: New York, NY, USA, 1994.

32. Hoge, E.; Bui, E.; Marques, L.; Metcalf, C.; Morris, L.; Robinaugh, D.; Worthington, J.; Pollack, M.; Simon, N. Randomized controlled trial of mindfulness meditation for generalized anxiety disorder: Effects on anxiety and stress reactivity. J. Clin. Psychiatry 2013, 74, 786-792. [CrossRef] [PubMed]

33. Hyperion, M.L.; Hopthrow, T.; Randsley de Moura, G. A moment of mindfulness: Computer-mediated mindfulness practice increases state mindfulness. PLoS ONE 2016, 11, e0153923.

34. Moore, A.; Malinowski, P. Meditation, mindfulness and cognitive flexibility. Conscious. Cogn. 2009, 18, 176-186. [CrossRef]

35. Punthawanunt, S.; Yupapin, P. Meditation on a daily basis makes wise without violence. Yoga Phisio 2018, $4,1-4$.

36. Walsh, R.; Shapiro, S. The meeting of meditative disciplines and western psychology: A mutually enriching dialogue. Am. Psychol. 2006, 61, 227-239. [CrossRef]

37. Pornsuwancharoen, N.; Amiri, I.S.; Ali, J.; Youplao, P.; Yupapin, P. Meditation mathematical formalism and lorentz factor calculation based-on mindfulness foundation. Results Phys. 2018, 11, 1034-1038. [CrossRef]

38. Pornsuwancharoen, N.; Amiri, I.S.; Suhailin, F.H.; Aziz, M.S.; Ali, J.; Singh, G.; Yupapin, P. Micro-current source generated by a WGM of light within a stacked silicon-graphene-Au waveguide. IEEE Photonics Technol. Lett. 2017, 29, 1768-1771. [CrossRef]

39. Prabhu, A.M.; Alan, T.; Zhanghua, H.; Vien, V. Extreme miniaturization of silicon add-drop microring filters for VLSI photonics applications. IEEE Photonics J. 2010, 2, 436-444. [CrossRef]

40. Blaber, M.G.; Arnold, M.D.; Ford, M.J. Search for the ideal plasmonic nanoshell: The effects of surface scattering and alternatives to gold and silver. J. Phys. Chem. C 2009, 113, 3041-3045. [CrossRef]

(C) 2020 by the authors. Licensee MDPI, Basel, Switzerland. This article is an open access article distributed under the terms and conditions of the Creative Commons Attribution (CC BY) license (http://creativecommons.org/licenses/by/4.0/). 